\title{
Understanding Treatment Preferences of Australian Patients Living with Treatment-Resistant Depression
}

\author{
Simon Fifer ${ }^{\prime}$ \\ Andrea Puig $\mathbb{D}^{2}$ \\ Vanessa Sequeira ${ }^{3}$ \\ Mustafa Acar $\mathbb{D D}^{2}$ \\ Chee $\mathrm{H} \mathrm{Ng} \mathbb{B D}^{4}$ \\ Michelle \\ Blanchard (iD ${ }^{5}$ \\ Ariana Cabrera $^{6}$ \\ James Freemantle (iD ${ }^{7}$ \\ Jennifer Grunfeld (D) 8
}

'Research and Innovation, Community and Patient Preference Research, Sydney, New South Wales, Australia; ${ }^{2}$ Real World Evidence, Janssen Australia, Macquarie Park, New South Wales, Australia; ${ }^{3}$ Medical Affairs, Janssen Australia, Macquarie Park, New South Wales, Australia; ${ }^{4}$ Professorial Unit, The Melbourne Clinic, Department of Psychiatry, University of Melbourne, Richmond, Victoria, Australia; ${ }^{5}$ Melbourne School of Psychological Sciences, University of Melbourne, Parkville, Victoria, Australia; ${ }^{6}$ Data Analytics and Visualisation, Community and Patient Preference Research, Sydney, New South Wales, Australia; ${ }^{7}$ People Measures, South Melbourne, Victoria, Australia; ${ }^{8}$ Peninsula Therapeutic \& Research Group, Frankston, Victoria, Australia
Correspondence: Andrea Puig Real World Evidence, Janssen Australia, 66 Waterloo Road, Macquarie Park, NSW, 2113 , Australia

Tel +6I-4-29|2-8695

Fax +6I 298153200

Email apuig@ITS.JNJ.com
Background: There is evidence of improved adherence and treatment outcomes when patients' treatment preferences are considered, and shared decision making is utilized.

Purpose: We aimed to better understand treatment preferences among Australians with treatment-resistant depression (TRD), focusing on the specific treatment attributes that people value (such as effectiveness, risk of side effects and cost) and their relative importance. The risk-benefit trade-offs that characterize treatment choices were also examined.

Patients and Methods: An online survey of 75 patients with experience of TRD was conducted, consisting of two discrete choice experiment (DCE) components - a medication DCE and a treatment plan DCE. Participants were able to prioritize and trade off different features of medications and treatment plans. Additional questions aimed to better define this population group, which in Australia is poorly understood.

Results: In both DCEs, two distinct latent classes were identified. In the medication DCE, the classes were distinguished by willingness to consider new treatment alternatives. Participants in class 1 were reluctant to give up current treatment, while those in the slightly larger class 2 preferred new treatment options. In both classes, treatment effectiveness and cost were the greatest contributors to preference. Similar behavior was seen in the treatment plan DCE, with the larger class more likely to choose a new plan over their current treatment arrangement. Participants preferred medications that were low-cost, taken orally, had a high percentage improvement in mood symptoms, high rate of remission and low risk of weight gain. A similar result was found in preferences for treatment plans such that plans with the greatest effectiveness and lowest cost were most favorable.

Conclusion: Patient preferences should routinely be considered and discussed to guide informed decisions regarding the value of new and existing medications for TRD and how they sit in the context of treatment plans.

Keywords: patient preferences, patient value mapping, behavioral economics, major depressive disorder, quantitative research, patient centricity

\section{Introduction}

While there are a variety of treatments for depression, an inadequate response to multiple treatments is not uncommon, affecting an estimated one-third of adult patients with depression. ${ }^{1}$ Patient involvement in discussions and decision-making around treatment choice may lead to improved adherence and subsequently improved treatment outcomes, ${ }^{2-4}$ and active involvement of patients in treatment decisions is increasingly viewed as an ethical imperative in all areas of healthcare. ${ }^{5,6}$ Current guidelines from the Royal Australian and New Zealand College of Psychiatrists ${ }^{7,8}$ recommend that patient preferences be taken into account when considering treatment choices for depression. 
In general, involvement in shared decision making and receiving preferred treatments allows for higher treatment satisfaction and completion, as well as improved clinical outcomes. ${ }^{10,11}$

While there is evidence of improved outcomes when patients' treatment preferences are taken into account and shared decision making is utilized, ${ }^{2}$ more research is needed on the efficacy of shared decision making in mental health. ${ }^{5}$ One recent systematic review and metaanalysis found significantly lower dropout rates and a significantly stronger therapeutic alliance when patients with a mental health diagnosis received their preferred psychosocial treatment. ${ }^{11}$ However, few studies have been designed to explicitly examine the impact of patient preferences on outcomes in major depressive disorder, particularly outside the context of controlled clinical trials. ${ }^{12}$ In addition, many existing studies focus on comparing preferences for medication versus psychological treatment $^{12,13}$ or on treatment preferences within the same type of treatment (for example different psychological therapies), ${ }^{14,15}$ when in practice treatment may involve multiple modes of treatment, often used together.

When examining patient preferences, it is important to understand what matters most to patients as individuals based on the most relevant benefits and harms. ${ }^{9}$ People place different importance on the outcomes associated with different options, and have varied preferences about how these outcomes are reached. ${ }^{9}$ Factors such as disease severity and duration, clinical presentation (symptoms), comorbidities, previous treatment responses and side effects, cost and convenience may be used to inform treatment decisions and potential effectiveness of a treatment.

In this study, we aimed to examine and understand treatment choices - both for individual medications (given via various routes of administration) and treatment plans involving multiple forms of treatment used successively or concurrently - among people with treatmentresistant depression (TRD). The study was divided in this way to explore in-depth treatment preferences for pharmacotherapies while acknowledging that these are not the only treatments used to combat TRD, and preferences for a broader and more holistic treatment approach also need to be evaluated.

While there is no universally accepted definition of TRD, all definitions reference a failure to respond to at least one adequate trial of antidepressant medication, ${ }^{16}$ and at least half of the currently used definitions reference non-response to at least two antidepressants. ${ }^{17}$ To be considered to have TRD in this study, participants must have had an inadequate response (estimated less than $50 \%$ response) to at least two antidepressant medications, each given for at least 6 weeks, during the last depressive episode. This reflected the definition used in the 2015 Royal Australian and New Zealand College of Psychiatrists Clinical Practice Guidelines for Mood Disorders ${ }^{7}$ (which was current at the time of this study) where TRD was "defined as a lack of improvement following adequate trials of two or more antidepressants".

Our study examined the specific treatment attributes that people value, their relative importance and the riskbenefit trade-offs that characterize patient choices around treatment options in TRD. To our knowledge, this is the first study of its kind examining patient preferences in people with TRD in Australia.

\section{Patients and Methods}

Patient preference research methods were used to measure the needs and views (values) of people with TRD. A choice modelling approach was designed to find out how current and new treatments are perceived, and what is most important to people when evaluating treatments. The study was approved by Bellberry Limited Human Research Ethics Committee (approval number 2017-04-273-A-3) and was conducted in accordance with the Declaration of Helsinki.

\section{Discrete Choice Experiments}

This study used a Discrete Choice Experiment (DCE) approach to gain an understanding of the treatment preferences of patients with TRD. DCEs have a firm theoretical background, grounded in psychology and economics. ${ }^{18-20}$ These methods are now commonly used in health to understand preferences. ${ }^{21}$ DCEs involve a survey (questionnaire) that presents participants with scenarios and asks them to choose an alternative within that scenario that maximizes their satisfaction (utility) based on their own value framework (Figure 1).

\section{Discrete Choice Experiment Design and Development}

\section{Attribute Development}

Qualitative research (in-depth interviews) with nine people experiencing TRD was conducted by Community and Patient Preference Research (CaPPRe) in August 2018 to gain a deeper understanding of the experiences and challenges in the treatment of depression. The 


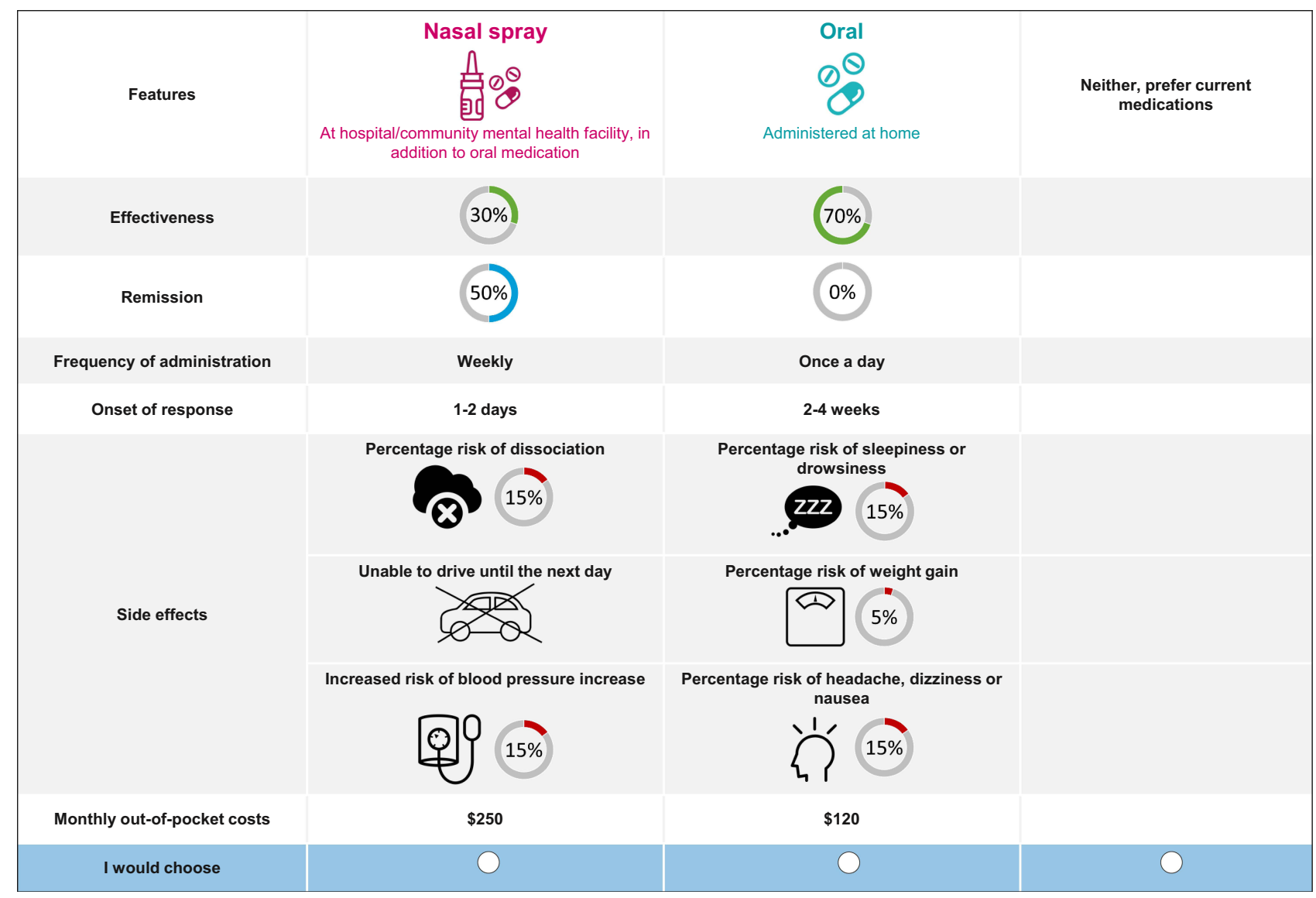

Figure I Screenshot of an example of a medication DCE scenario with explanations of the task.

qualitative in-depth interviews (plus review of existing literature, evidence from clinical trials and currently funded treatments and consultation with a steering research committee of subject matter experts) informed the key themes, design, attributes and appropriate terminology used in the quantitative stage of the study - the two DCEs. Qualitative interviews provide a high level of richness of attributes, and the use of both qualitative interviews and literature searching reduced the potential for attribute misspecification. ${ }^{22}$

\section{Participants}

Each of the nine participants underwent a clinical screening interview with a clinician to confirm they met the criteria for TRD, before an in-depth telephone interview (which lasted 60 minutes). A major depressive episode was diagnosed using the Major Depressive Episode Module of The Mini International Neuropsychiatric Interview (M.I.N.I) version 7.0.0 for DSM-5. Treatment resistance was evaluated using questions from the Antidepressant Treatment Response Questionnaire $(\mathrm{ATRQ})^{23}$ and defined as $<50 \%$ response to at least two antidepressant medications, each taken at a pre-defined minimum effective dose for at least 6 weeks during the depressive episode.

\section{Attribute Development}

Based on the qualitative interviews and literature search, attributes were developed. Attributes in the DCEs included key clinical characteristics of the medications or treatment plans that were considered important for an individual with TRD in coming to a decision about which treatment to take for their depression. ${ }^{22}$ For example, effectiveness, remission, side effects and cost. Each attribute was assigned different levels, for example the percentage improvement in mood symptoms had levels of $10 \%$, $30 \%, 50 \%$ and $70 \%$ (attributes and levels are listed in Supplementary Tables 1 and 2).

\section{Experimental Design and Sample Size}

In DCEs, the objective is to determine the influence of the design attributes upon the choices that are made by respondents undertaking the experiment. Responses are 
pooled to obtain statistically reliable parameter estimates. As such, DCEs consist of numerous respondents being asked to complete a number of choice scenarios in which they are asked to select one or more alternatives from a finite set of alternatives. The total number of scenarios answered provides the number of observations for modeling purposes (ie, a single participant provides multiple data points or observations).

Sample size calculations are not typically performed in DCEs, as these require a priori knowledge of expected parameter estimates.

Approximations of the minimum required sample size are calculated based on the utility function to be estimated (which is a function of the number of parameters) during the experimental design process. In this study, a Bayesian efficient design approach was used to input knowledge about known prior attribute levels or coefficients (including magnitude and direction) to optimize the design for sample constraints. The sample size in this study was chosen using the method of Johnson and Orme, ${ }^{24}$ based on the number of choice sets $(t)$, the number of alternatives (a), and the number of analysis cells (c) according to the following equation: $\mathrm{N}>500 \mathrm{c} /(\mathrm{t} \times \mathrm{a})$. An additional requirement is that the number of choice sets must be greater than the number of parameters to be estimated. Both these design requirements were met in this study.

The combinations of levels presented in the DCE instrument were designed using a D-efficient availability design structure using naïve priors to account for the sign of the parameters and level order in Ngene. ${ }^{25}$ The study and experimental designs followed good practice guidelines. $^{26,27}$

\section{DCE Experiment}

\section{Participants}

A 30-minute online survey of 75 people in Australia with treatment-resistant depression was conducted during the period from March 2019 to August 2019. Participants were recruited from online market research panels, including Stable Research, Dynata and QRA; consumer groups, including SANE Australia and One Door Mental Health; and through information distributed to patients by their treating psychiatrists. Participants had been previously diagnosed with depression by a healthcare professional (for example, general practitioner, psychiatrist or psychologist) and were currently experiencing (or had previously experienced) a major depressive episode. Treatment resistance was evaluated using the efficacy and duration criteria from the
ATRQ, such that participants must have had an inadequate response ( $<50 \%$ improvement in depressive symptoms) to at least two antidepressants (or medications prescribed for their antidepressant effect) taken for at least 6 weeks.

Participants were aged 18 years and older and gave informed consent by reading the online participant information sheet and indicating their consent by ticking a box. Participants were able to withdraw at any time without penalty or prejudice. Those who completed the survey were given the choice between being reimbursed $\$ 40$ as a direct payment or as a donation to SANE Australia. Participants were excluded if they self-reported that they worked for a pharmaceutical company or had lifetime comorbidities including bipolar disorder, intellectual disability, dementia or traumatic/acquired brain injury, psychotic disorders, personality disorders, autism spectrum disorders, organic mood disorders or attention deficithyperactivity disorder. People were also excluded if, during the relevant depressive episode they had comorbidities including post-traumatic stress disorder, obsessive compulsive disorder, eating disorders, substance use disorders or chronic pain.

\section{Instrument}

The survey instrument consisted of a DCE component, which involved selecting a preferred alternative from a set of competing alternatives, and additional questions that were designed to understand the clinical characteristics of the patient sample. The DCE component was in two parts, a medication DCE and a treatment plan DCE, designed to accurately reflect the broad range of treatments available to people experiencing TRD and the fact that at any given time, people may be receiving one or several different treatments (such as medications, psychological treatments, physical treatments, complementary therapies and lifestyle interventions).

\section{Medication DCE}

A labelled availability DCE design was used to examine people's preferences for different pharmacological treatments. The medication DCE design consisted of 96 scenarios split into 6 blocks so that each participant was presented with 16 scenarios.

In each scenario, participants were asked to choose their preferred treatment option from two hypothetical alternatives and their current medications. The hypothetical treatments were labelled by mode of administration: oral; nasal spray (administered in addition to oral 
medication); and infusion. An availability design was used to show only two out of three labelled alternatives at a time. Attributes included in the DCE were effectiveness, remission, frequency of administration, onset of response, risk of side effects and monthly out-of-pocket costs. Detailed definitions of these terms were included in an instruction page prior to completing the task and are provided in Supplementary Table 1. In addition, participants were shown an annotated screenshot of an example DCE scenario to familiarize them with the upcoming scenarios (Figure 1). Levels shown in each scenario were not selected at random but rather selected and positioned according to the experimental design.

\section{Treatment Plan DCE}

An unlabeled DCE design was used to examine people's preferences for different treatment plans or profiles that included combinations of various different treatments. The treatment plan DCE design consisted of 72 scenarios split into 9 blocks so that each participant was presented with 8 scenarios.

In each scenario, participants were asked to choose their preferred treatment plan from two hypothetical alternatives, presented as "Treatment Plan A" and "Treatment Plan B", and their current treatment plan. Attributes used in the DCE to describe the hypothetical alternatives were effectiveness (percentage improvement in mood symptoms), remission (proportion of people whose mood symptoms are controlled or have disappeared after treatment), medication, psychotherapy, brain stimulation (electroconvulsive therapy and transcranial magnetic stimulation), lifestyle changes, mindfulness, primary healthcare practitioner, setting and monthly out-of-pocket costs. Descriptions of these attributes, as provided to participants before completing the task, are presented in Supplementary Table 2; and a screenshot of an example DCE scenario with explanations is displayed in Figure 2.

\section{Analysis}

Participant demographics and treatment characteristics were summarized descriptively. The model structure was based on principles of Random Utility Theory (see Supplementary text). To overcome the limitations associated with standard models (multinomial logit models [MNL]), a latent class model (LCM) was used to model the DCE. This model allows for preference heterogeneity, which is handled using a discrete distribution of "classes" (see also Supplementary text and Supplementary Figure 1).

The LCM was specified to measure alternative specific parameter estimates, where each treatment feature for each mode has a specific parameter estimate compared to a reference category. For example, for the treatment mode, parameters were specified for nasal spray, oral administration or infusion compared to current treatment.

Initially, full models were built that included all attributes. Reduced models removed those attributes that were insignificant within the full model. The number of classes and model fit were assessed using Akaike's information criterion (AIC) and Bayesian information criterion (BIC), with the model that minimized these criteria being selected. The relative importance of each attribute was calculated by finding the maximum difference in utility between the attribute's levels and expressing it as a percentage of the sum of all maximum differences. Statistical analyses were performed in Nlogit version 6 (Econometric Software, Inc.) and values of $\mathrm{p}<0.05$ were considered statistically significant.

\section{Results}

A total of 75 people participated in the survey. Data were cleaned and extracted from the responses of 61 participants in the medication DCE model (14 participants were removed due to incomplete responses) and all 75 participants for the treatment plan DCE model and for descriptive and demographic analysis.

\section{Population Demographics}

The demographics of participants included in the DCE are reported in Table 1. The average age of the total sample was 39 years and $60 \%$ of the sample was male. The majority of participants lived in the eastern states of Australia - New South Wales (25\%), Victoria (22\%) and Queensland (21\%), predominantly in metropolitan areas, and two participants identified as being of Aboriginal background.

\section{Diagnosis and Treatment History}

The study included 71 people currently experiencing a major depressive episode and four people who had previously experienced a major depressive episode. Diagnosis and treatment history results are reported in Table 2.

Most participants (71\%) were first diagnosed with depression more than five years ago. The current/previous episode of depression was most often diagnosed by a general practitioner $(63 \%)$, and the majority of participants $(91 \%)$ had a general practitioner involved in 


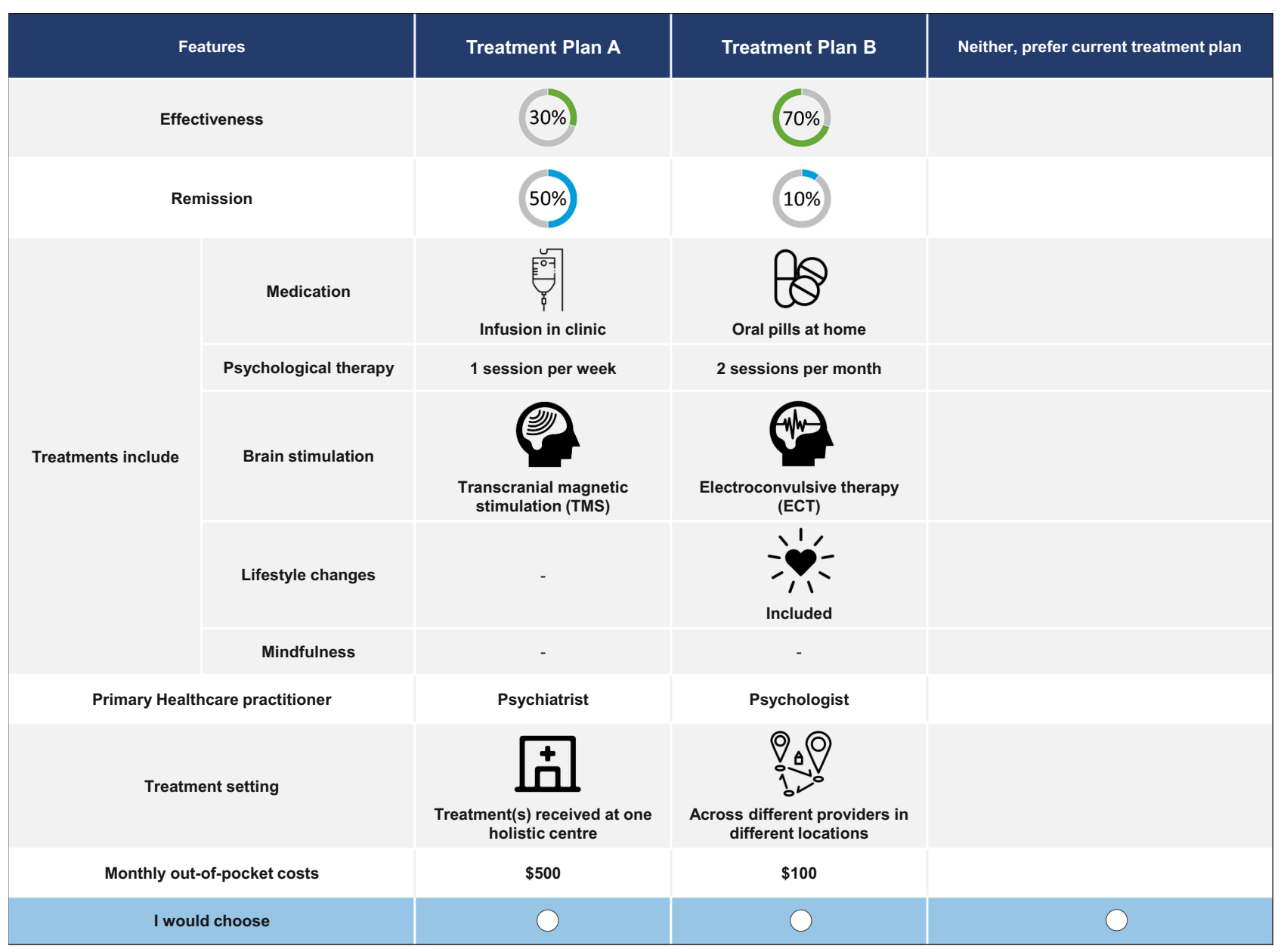

Figure 2 Screenshot of an example of a treatment plan DCE scenario with explanations.

managing the current/previous episode of depression. In addition, comorbid anxiety disorders were common, with $71 \%$ of participants reporting being diagnosed with anxiety disorders during the depressive episode.

The most common treatments tried in the current/previous episode of depression were antidepressant medications (97\%) and psychological therapies (60\%). Approximately half of all participants experienced the medication side effects of weight gain (48\%), difficulty sleeping or drowsiness (59\%) and/or fatigue (49\%), which impacted them with varying degrees of severity.

Lifestyle changes (62\%) and mindfulness (55\%) were commonly tried among people currently experiencing an episode of depression, and participants were given the opportunity to report any other therapies they had tried for symptom relief.

\section{Income and Out-of-Pocket Expenses}

Monthly out-of-pocket expenses associated with depression and annual personal and total household incomes are reported in Table 1. The median cost for those experiencing a current episode of depression was $\$ 100$ per month (interquartile range $\$ 50$ to $\$ 300$ ). For those with a previous episode of depression, median monthly costs were \$240 (IQR \$100 to \$390).

\section{Medication DCE}

Each participant completed one block of the overall design, which included 16 scenarios during the medication DCE task. The best fitting model was a latent class model (LCM) with two classes of participants, based on their preferences for TRD medication and evaluated using AIC and BIC criteria. The estimated utility functions are shown below and the DCE model output is presented in Table 3 (explanations of beta coefficients can also be found in Table 3). In general, the larger the coefficient, the more impact it has on utility (assuming levels have the same type of coding, eg, dummy coding). 
Table I Basic Demographics of the Total Sample and Medication DCE Sample

\begin{tabular}{|c|c|c|c|}
\hline & Characteristic & Total Sample $(n=75)$ & Medication DCE Sample $(n=61)$ \\
\hline \multirow[t]{2}{*}{ Gender - n (\%) } & Female & $30(40.0)$ & $26(42.6)$ \\
\hline & Male & $45(60.0)$ & $35(57.4)$ \\
\hline \multirow[t]{7}{*}{ Occupational status - n (\%) } & Working full-time & $23(30.7)$ & $18(29.5)$ \\
\hline & Working part-time & $16(21.3)$ & $12(19.7)$ \\
\hline & Working casual & $9(12.0)$ & $8(13.1)$ \\
\hline & Not working & 14 (18.7) & II (I8.0) \\
\hline & Home duties and/or caring & $9(12.0)$ & $8(13.1)$ \\
\hline & responsibilities & & \\
\hline & Retired & $4(5.3)$ & $4(6.6)$ \\
\hline \multirow[t]{6}{*}{ Household type - n (\%) } & Couple with no children & $20(26.7)$ & $17(27.9)$ \\
\hline & Couple family with children & $22(29.3)$ & $21(34.4)$ \\
\hline & One parent family & $8(10.7)$ & $4(6.6)$ \\
\hline & Single person household & $14(18.7)$ & II (I8.0) \\
\hline & Group household & $10(13.3)$ & 7 (II.5) \\
\hline & Prefer not to answer & $\mathrm{I}(\mathrm{I} .3)$ & I (I.6) \\
\hline \multirow[t]{3}{*}{ Area of residence $-\mathrm{n}(\%)$} & Metro/city & $51(68.0)$ & $40(65.6)$ \\
\hline & Regional & $22(29.3)$ & $19(31.1)$ \\
\hline & Rural & $2(2.7)$ & $2(3.3)$ \\
\hline \multirow{5}{*}{$\begin{array}{l}\text { Annual total gross personal income (before } \\
\operatorname{tax})-n(\%)\end{array}$} & Nil income & $8(10.7)$ & $7(11.5)$ \\
\hline & $<\$ 26,000$ & $26(34.7)$ & $21(34.4)$ \\
\hline & $\$ 26,000-\$ 5 I, 999$ & $20(26.7)$ & I5 (24.6) \\
\hline & $\$ 52,000-\$ 88,399$ & $17(22.7)$ & $14(23.0)$ \\
\hline & $\$ 88,400$ or more & $4(5.3)$ & $4(6.6)$ \\
\hline \multirow{7}{*}{$\begin{array}{l}\text { Annual gross household income (before } \\
\operatorname{tax})-n(\%)\end{array}$} & Nil income & $2(2.7)$ & I (I.6) \\
\hline & $<\$ 26,000$ & $9(12.0)$ & $7(11.5)$ \\
\hline & $\$ 26,000-\$ 5 I, 999$ & I5 (20.0) & II (I8.0) \\
\hline & $\$ 52,000-\$ 88,399$ & $21(28.0)$ & I7 (27.9) \\
\hline & $\$ 88,400-\$ 155,999$ & $19(25.3)$ & $16(26.2)$ \\
\hline & $\$ 156,000$ or more & $6(8.0)$ & $6(9.8)$ \\
\hline & Prefer not to answer & $3(4.0)$ & $3(4.9)$ \\
\hline
\end{tabular}

$$
\begin{aligned}
U(\text { Oral })= & \beta_{o C O N}+\beta_{o E F 30} x_{o E F 30}+\beta_{o E F 50} x_{o E F 50} \\
& +\beta_{o E F 70} x_{o E F 70}+\beta_{o R E M 10} x_{o R E M 10} \\
& +\beta_{o R E M 30} x_{o R E M 30}+\beta_{o R E M 50} x_{o R E M 50} \\
& +\beta_{o W G 5} x_{o W G 5}+\beta_{o C S T 1} x_{o C S T 1}+\beta_{o C S T 2} x_{o C S T 2} \\
& +\beta_{o C S T 3} x_{o C S T 3}
\end{aligned}
$$

$$
\begin{aligned}
U(\text { Nasal })= & \beta_{n C O N}+\beta_{n E F 30} x_{n E F 30}+\beta_{n E F 50} x_{n E F 50} \\
& +\beta_{n E F 70} x_{n E F 70}+\beta_{n R E M 30} x_{n R E M 30} \\
& +\beta_{n R E M 50} x_{n R E M 50}+\beta_{n i C S T 1} x_{n C S T 1} \\
& +\beta_{n i C S T 2} x_{n C S T 2}+\beta_{n i C S T 3} x_{n C S T 3}
\end{aligned}
$$

$$
\begin{aligned}
U(\text { Infusion })= & \beta_{i C O N}+\beta_{i E F 30} x_{i E F 30}+\beta_{i E F 50} x_{i E F 50} \\
& +\beta_{i E F 70} x_{i E F 70}+\beta_{i R E M 30} x_{i R E M 30} \\
& +\beta_{i R E M 50} x_{i R E M 50}+\beta_{n i C S T 1} x_{i C S T 1} \\
& +\beta_{n i C S T 2} x_{i C S T 2}+\beta_{\text {niCST3 }} x_{i C S T 3}
\end{aligned}
$$

$$
U(\text { Current })=0
$$

The average class membership probabilities were $39.4 \%$ for class 1 and $60.6 \%$ for class 2 . Demographic characteristics and treatment history variables were not significantly associated with class membership.

"Class 1" participants had a preference for their current treatment over new alternatives - that is, they had a negative parameter estimate compared to current treatment for the alternative specific constants nasal $(-2.755$, SE 1.028), oral (-0.879, SE 0.508) and infusion (-1.573, SE 0.546) forms of treatment - while "class 2 “ participants preferred a new alternative over their current treatment (positive estimates for the alternative specific constant; 0.555 (SE 0.298), 1.376 (SE 0.331) and 1.006 
Table 2 Diagnosis and Treatment History Results

\begin{tabular}{|c|c|c|c|}
\hline & Characteristic & Current Episode $(n=7 I)$ & Previous Episode $(n=4)$ \\
\hline $\begin{array}{l}\text { Time since first diagnosed with } \\
\text { depression }-\mathrm{n}(\%)\end{array}$ & $\begin{array}{l}\text { In the last } 6 \text { months } \\
\text { In the last } 6-12 \text { months } \\
1-2 \text { years ago } \\
2-5 \text { years ago } \\
\text { More than } 5 \text { years ago } \\
\text { Do not know }\end{array}$ & $\begin{array}{l}\text { I }(1.4) \\
2(2.8) \\
5(7.0) \\
11(15.5) \\
51(71.8) \\
1(1.4)\end{array}$ & $\begin{array}{l}0 \\
0 \\
\text { I (25) } \\
\text { I (25) } \\
2(50) \\
0\end{array}$ \\
\hline $\begin{array}{l}\text { Diagnosed with anxiety disorders } \\
\text { during depressive episode }-n(\%)\end{array}$ & $\begin{array}{l}\text { Yes } \\
\text { No }\end{array}$ & $\begin{array}{l}50(70.4) \\
21(29.6)\end{array}$ & $\begin{array}{l}3(75) \\
\text { I (25) }\end{array}$ \\
\hline $\begin{array}{l}\text { Length of depressive episode - } \\
\mathrm{n}(\%)\end{array}$ & $\begin{array}{l}3-6 \text { months } \\
6-12 \text { months } \\
12-24 \text { months } \\
\text { More than } 24 \text { months }\end{array}$ & $\begin{array}{l}16(22.5) \\
11(15.5) \\
8(11.3) \\
36(50.7)\end{array}$ & $\begin{array}{l}2(50) \\
0 \\
2(50) \\
0\end{array}$ \\
\hline $\begin{array}{l}\text { Treatments tried during } \\
\text { depressive episode }-n^{a}\end{array}$ & $\begin{array}{l}\text { Antidepressants and medications prescribed for } \\
\text { antidepressant effect } \\
\text { Other prescription medications } \\
\text { Psychological therapy } \\
\text { Mindfulness } \\
\text { Electroconvulsive therapy (ECT) } \\
\text { Transcranial magnetic stimulation (TMS) } \\
\text { Lifestyle changes } \\
\text { Ketamine/esketamine } \\
\text { Other }\end{array}$ & $\begin{array}{l}69 \\
20 \\
42 \\
39 \\
7 \\
6 \\
44 \\
1 \\
3\end{array}$ & $\begin{array}{l}4 \\
2 \\
3 \\
0 \\
0 \\
0 \\
0 \\
0 \\
0\end{array}$ \\
\hline $\begin{array}{l}\text { Medications tried for at least } 6 \\
\text { weeks during depressive } \\
\text { episode }-\mathrm{n}^{\text {a }}\end{array}$ & $\begin{array}{l}\text { SSRIs (citalopram, escitalopram, fluoxetine, } \\
\text { fluvoxamine, paroxetine, sertraline, venlafaxine) } \\
\text { Atypical antipsychotics (aripiprazole, } \\
\text { olanzapine, quetiapine) } \\
\text { Tricyclic antidepressants (amitriptyline, } \\
\text { clomipramine, dothiepin, doxepin, nortriptyline, } \\
\text { trimipramine) } \\
\text { SNRIs (duloxetine, desvenlafaxine) } \\
\text { Tetracyclic antidepressants (mirtazapine, } \\
\text { mianserin) } \\
\text { Serotonin receptor activity modulators } \\
\text { (vortioxetine) } \\
\text { MAOls (phenelzine, tranylcypromine) } \\
\text { Noradrenaline reuptake inhibitors } \\
\text { (reboxetine) } \\
\text { RIMAs (moclobemide) } \\
\text { Melatonergic antidepressants (agomelatine) } \\
\text { Selective catecholamine reuptake } \\
\text { inhibitors (bupropion) }\end{array}$ & $\begin{array}{l}133 \\
36 \\
35 \\
\\
29 \\
19 \\
8 \\
7 \\
7 \\
7 \\
5 \\
1\end{array}$ & $\begin{array}{l}5 \\
2 \\
1 \\
2 \\
1 \\
0 \\
0 \\
0 \\
0 \\
0 \\
0\end{array}$ \\
\hline
\end{tabular}

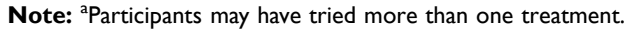

Abbreviations: SSRIs, selective serotonin reuptake inhibitors; SNRIs, serotonin noradrenaline reuptake inhibitors; MAOls, monoamine oxidase inhibitors; RIMAs, reversible inhibitors of monoamine oxidase $A$.

(SE 0.280), respectively, see Table 3). Of the new alternatives, oral medication with high rates of effectiveness (70\% improvement in mood symptoms; 1.238 , SE 0.343 ) and remission $(50 \%$ of participants had their mood symptoms controlled or relieved; 0.464, SE 0.280) was the most favored for class 2 , even at higher costs than a competing nasal spray or infusion alternative with the same features. 
Table 3 Model Output for Medication DCE

\begin{tabular}{|c|c|c|c|c|c|c|c|c|c|}
\hline \multirow{3}{*}{$\begin{array}{l}\text { Class Proportions } \\
\text { Utility Parameters }\end{array}$} & \multirow[t]{3}{*}{ Symbol } & \multicolumn{4}{|c|}{ Class I } & \multicolumn{4}{|c|}{ Class 2} \\
\hline & & \multicolumn{4}{|c|}{0.394} & \multicolumn{4}{|c|}{0.606} \\
\hline & & Parameter & & SE & T-Ratio & Parameter & & SE & T-Ratio \\
\hline \multicolumn{10}{|c|}{ Treatment mode constants } \\
\hline Oral & $o C O N$ & -0.829 & & 0.508 & -1.630 & 1.376 & $*$ & 0.331 & 4.160 \\
\hline Nasal spray & $n C O N$ & -2.755 & $*$ & 1.028 & -2.680 & 0.555 & & 0.298 & 1.860 \\
\hline Infusion & $i C O N$ & -1.573 & $*$ & 0.546 & -2.880 & 1.006 & $*$ & 0.280 & 3.590 \\
\hline \multicolumn{10}{|c|}{ (Reference category: Current treatment) } \\
\hline \multicolumn{10}{|l|}{ Effectiveness } \\
\hline \multicolumn{10}{|l|}{ Oral } \\
\hline $30 \%$ improvement & $o E F 30$ & 0.830 & & 0.494 & 1.680 & 0.556 & & 0.318 & 1.750 \\
\hline $50 \%$ improvement & $o E F 50$ & 2.019 & $*$ & 0.500 & 4.040 & 0.959 & $*$ & 0.324 & 2.960 \\
\hline $70 \%$ improvement & $o E F 70$ & 1.911 & $*$ & 0.51 & 3.750 & 1.238 & $*$ & 0.343 & 3.610 \\
\hline \multicolumn{10}{|c|}{ (Reference category: $10 \%$ ) } \\
\hline \multicolumn{10}{|l|}{ Nasal spray } \\
\hline $30 \%$ improvement & $n E F 30$ & 0.869 & & 1.202 & 0.720 & 1.009 & $*$ & 0.355 & 2.840 \\
\hline $50 \%$ improvement & $n E F 50$ & 2.489 & $*$ & 1.110 & 2.240 & 1.343 & $*$ & 0.338 & 3.970 \\
\hline $70 \%$ improvement & $n E F 70$ & 3.407 & $*$ & 1.139 & 2.990 & 1.833 & $*$ & 0.345 & 5.310 \\
\hline \multicolumn{10}{|c|}{ (Reference category: I0\%) } \\
\hline \multicolumn{10}{|l|}{ Infusion } \\
\hline $30 \%$ improvement & $i E F 30$ & 0.443 & & 0.714 & 0.620 & 0.064 & & 0.342 & 0.190 \\
\hline $50 \%$ improvement & $i E F 50$ & 0.317 & & 0.838 & 0.380 & 0.934 & $*$ & 0.342 & 2.730 \\
\hline $70 \%$ improvement & $i E F 70$ & 2.173 & $*$ & 0.737 & 2.950 & 1.092 & $*$ & 0.338 & 3.230 \\
\hline \multicolumn{10}{|c|}{ (Reference category: $10 \%$ ) } \\
\hline \multicolumn{10}{|l|}{ Remission } \\
\hline \multicolumn{10}{|l|}{ Oral } \\
\hline $10 \%$ & oREM10 & 0 & & \multirow{2}{*}{\multicolumn{2}{|c|}{$\begin{array}{l}\text { Fixed parameter } \\
\text { Fixed parameter }\end{array}$}} & 0 & & \multirow{2}{*}{\multicolumn{2}{|c|}{$\begin{array}{l}\text { Fixed parameter } \\
\text { Fixed parameter }\end{array}$}} \\
\hline $30 \%$ & oREM30 & 0 & & & & 0 & & & \\
\hline $50 \%$ & oREM50 & -0.146 & & 0.382 & -0.380 & 0.464 & & 0.280 & 1.660 \\
\hline \multicolumn{10}{|c|}{ (Reference category: $0 \%$ ) } \\
\hline \multicolumn{10}{|l|}{ Nasal spray } \\
\hline $30 \%$ & $n R E M 30$ & 0 & & & arameter & 0 & & & arameter \\
\hline $50 \%$ & $n R E M 50$ & 0 & & & arameter & 0 & & & arameter \\
\hline \multicolumn{10}{|c|}{ (Reference category: 10\%) } \\
\hline \multicolumn{10}{|l|}{ Infusion } \\
\hline $30 \%$ & $i R E M 30$ & 0 & & & arameter & 0 & & & arameter \\
\hline $50 \%$ & $i R E M 50$ & 0 & & & arameter & 0 & & & arameter \\
\hline
\end{tabular}


Table 3 (Continued).

\begin{tabular}{|c|c|c|c|c|c|c|c|c|c|}
\hline \multirow{3}{*}{$\begin{array}{l}\text { Class Proportions } \\
\text { Utility Parameters }\end{array}$} & \multirow[t]{3}{*}{ Symbol } & \multicolumn{4}{|c|}{ Class I } & \multicolumn{4}{|c|}{ Class 2} \\
\hline & & \multicolumn{4}{|c|}{0.394} & \multicolumn{4}{|c|}{0.606} \\
\hline & & Parameter & & SE & T-Ratio & Parameter & & SE & T-Ratio \\
\hline \multicolumn{10}{|l|}{ Risk of weight gain } \\
\hline \multicolumn{10}{|l|}{ Oral } \\
\hline $5 \%$ risk & oWG5 & 0.683 & $*$ & 0.338 & 2.020 & 0.047 & & 0.250 & 0.190 \\
\hline \multicolumn{10}{|c|}{ (Reference category: $10-15 \%$ risk) } \\
\hline \multicolumn{10}{|c|}{ Monthly out of pocket cost } \\
\hline \multicolumn{10}{|l|}{ Oral } \\
\hline$\$ 120-\$ 160$ & $o C S T 1$ & -1.548 & $*$ & 0.466 & -3.320 & -0.125 & & 0.327 & -0.380 \\
\hline$\$ 200-\$ 240$ & $o C S T 2$ & -1.495 & $*$ & 0.486 & -3.080 & -0.337 & & 0.322 & -1.050 \\
\hline$\$ 280-\$ 320$ & oCST3 & -1.719 & $*$ & 0.456 & -3.770 & -0.367 & & 0.321 & -1.140 \\
\hline \multicolumn{10}{|c|}{ (Reference category: $\$ 40-\$ 80$ ) } \\
\hline \multicolumn{10}{|c|}{ Nasal spray and Infusion (Class I) } \\
\hline$\$ 500$ & niCST1 & -1.976 & $*$ & 0.563 & -3.510 & - & & - & - \\
\hline$\$ 750$ & niCST2 & -3.131 & $*$ & 1.077 & -2.910 & - & & - & - \\
\hline$\$ 1000-\$ 2500$ & niCST3 & -3.950 & $*$ & 0.677 & -5.840 & - & & - & - \\
\hline \multicolumn{10}{|c|}{ (Reference category: $\$ 100-\$ 250$ ) } \\
\hline \multicolumn{10}{|c|}{ Nasal spray and Infusion (Class 2) } \\
\hline$\$ 1500$ & niCST1 & - & & - & - & -0.711 & $*$ & 0.204 & -3.490 \\
\hline$\$ 2000$ & niCST2 & - & & - & - & -1.004 & $*$ & 0.288 & -3.490 \\
\hline$\$ 2500$ & niCST3 & - & & - & - & -1.358 & $*$ & 0.303 & -4.480 \\
\hline
\end{tabular}

Notes: *Statistically significant at the 5\%-level. Restricted log-likelihood: - 1353.023; Log-likelihood: -759.434; McFadden Pseudo R-squared: 0.439; Number of respondents: 6I; Number of choice observations: 976. All categorical attributes were dummy coded and should be compared to the reference category. Omitted attributes: frequency of administration, onset of response, risk of dissociation (nasal spray and infusion only), ability to drive the next day (nasal spray and infusion only), risk of blood pressure increase (nasal spray and infusion only), risk of sleepiness or drowsiness (oral only) and risk of headache, dizziness or nausea (oral only).

Overall, treatment preference significantly decreased as cost increased, with a large negative effect for nasal spray and infusion treatments when the cost reached $\$ 750$ or more for class 1 (-3.131, SE 1.077), in contrast to the more gradual decrease starting at costs of $\$ 1500$ for class 2 (-0.711, SE 0.204). (See https://cappre.shinyapps.io/ JanssenTRD/, for a visual representation of the model results and Supplementary text and Supplementary Figure 2 for more information.)

Attributes with non-significant parameters for all three treatment alternatives (nasal spray, oral or infusion) included: frequency of administration; onset of response; risk of dissociation (nasal spray and infusion only); ability to drive the next day (nasal spray and infusion only); risk of blood pressure increase (nasal spray and infusion only); risk of sleepiness or drowsiness (oral only) and risk of headache; and dizziness or nausea (oral only). These attributes were removed in the final model and omitted from the LCM model output in Table 3.

Effectiveness and cost were the most important attributes for the nasal spray and infusion alternatives (Figures 3A and B). Across both forms of treatments, cost was most important (nasal spray 54\%; infusion $65 \%$ ), followed by effectiveness (nasal spray $46 \%$; infusion $35 \%$ ) in class 1 . Similarly, class 2 ranked cost first for infusion medications (55\%) but placed more importance on effectiveness for nasal spray medications $(57 \%)$. 

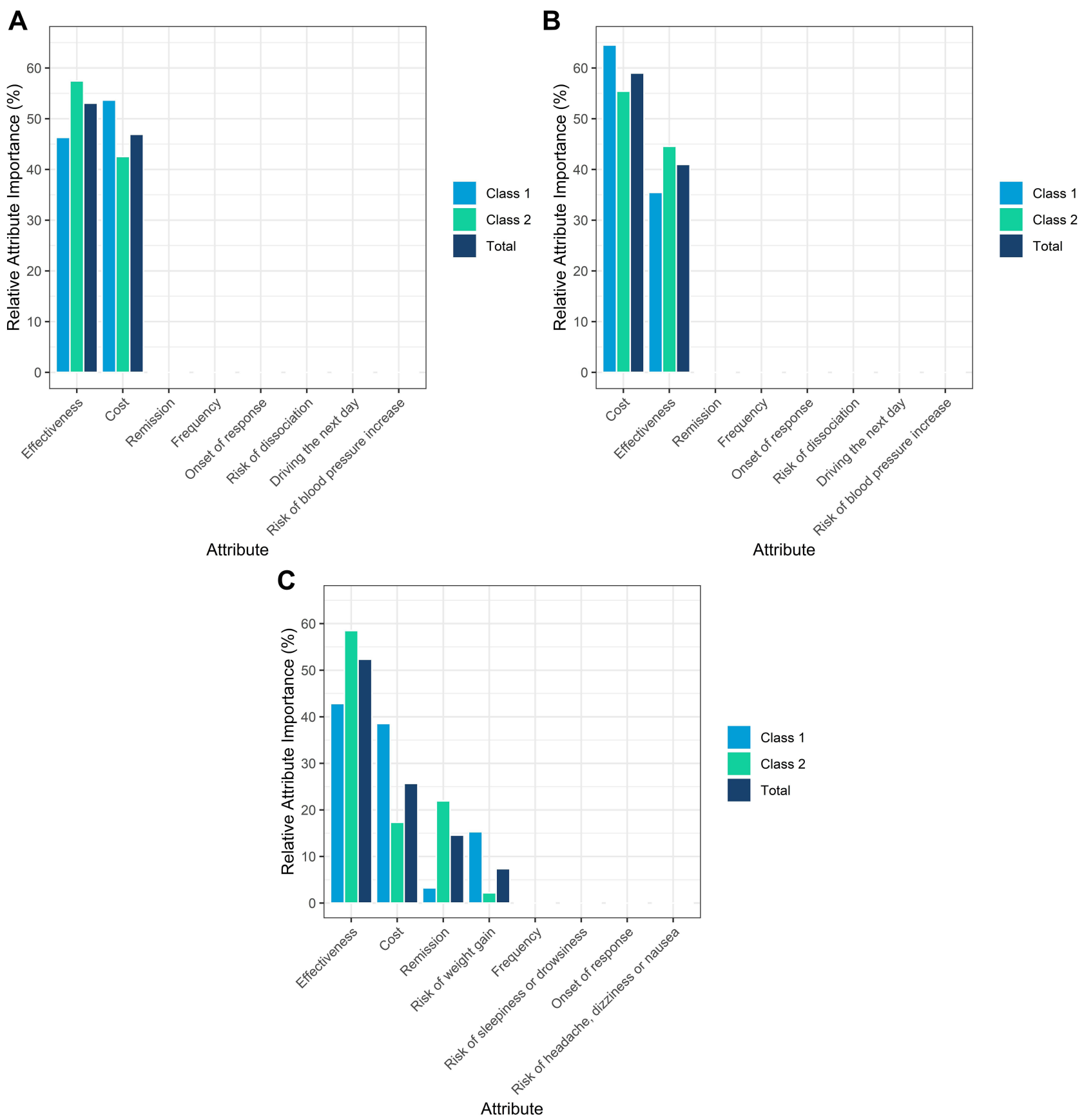

Figure 3 (A) Attribute importance for medication DCE: Nasal spray. (B) Attribute importance for medication DCE: Infusion. (C) Attribute importance for medication DCE: Oral.

For the oral treatment alternative, although effectiveness and cost largely dominated participant preferences (overall), remission and risk of weight gain also contributed to their choices (Figure 3C). Specifically, risk of weight gain influenced choices (15\%) for Class 1 , while remission $(22 \%)$ was seen to be more important than cost (17\%) for Class 2.

\section{Treatment Plan DCE}

Each participant completed one block of the overall design which included 8 scenarios in the treatment plan DCE task. All participants were included in this DCE analysis.

The best fitting model was a two-class LCM based on AIC and BIC criteria. The estimated utility functions are shown below and the model output is presented in Table 4 
Table 4 Model Output for Treatment Plan DCE

\begin{tabular}{|c|c|c|c|c|c|c|c|c|c|}
\hline \multirow{3}{*}{$\begin{array}{l}\text { Class Proportions } \\
\text { Utility Parameters }\end{array}$} & \multirow[t]{3}{*}{ Symbol } & \multicolumn{4}{|c|}{ Class I } & \multicolumn{4}{|c|}{ Class 2} \\
\hline & & \multicolumn{4}{|c|}{0.584} & \multicolumn{4}{|c|}{0.416} \\
\hline & & Parameter & & SE & T-Ratio & Parameter & & SE & T-Ratio \\
\hline Current treatment plan & $C O N$ & -1.189 & $*$ & 0.340 & -3.500 & 1.697 & $*$ & 0.443 & 3.830 \\
\hline \multicolumn{10}{|c|}{ (Reference category: Treatment A or B) } \\
\hline \multicolumn{10}{|l|}{ Treatment effectiveness } \\
\hline $50 \%$ improvement & EF50 & 1.368 & $*$ & 0.231 & 5.930 & 0.915 & $*$ & 0.461 & 1.980 \\
\hline $70 \%$ improvement & $E F 70$ & 1.855 & $*$ & 0.264 & 7.020 & 1.093 & $*$ & 0.470 & 2.320 \\
\hline \multicolumn{10}{|c|}{ (Reference category: $30 \%$ improvement) } \\
\hline \multicolumn{10}{|l|}{ Medication } \\
\hline Oral pills at home & $O R A L$ & 0.800 & $*$ & 0.212 & 3.780 & -0.470 & & 0.399 & -1.180 \\
\hline Nasal spray in clinic and oral & $N A S A L$ & 0.505 & $*$ & 0.188 & 2.330 & -0.630 & & 0.409 & -1.540 \\
\hline Infusion in clinic & $I N F$ & 0 & & \multicolumn{2}{|c|}{ Fixed parameter } & 0 & & \multicolumn{2}{|c|}{ Fixed parameter } \\
\hline \multicolumn{10}{|l|}{ (Reference category: None) } \\
\hline \multicolumn{10}{|l|}{ Brain stimulation } \\
\hline ECT & $E C T$ & -0.743 & $*$ & 0.240 & -3.100 & -0.521 & & 0.480 & -1.090 \\
\hline TMS & $T M S$ & 0 & & \multicolumn{2}{|c|}{ Fixed parameter } & 0 & & \multicolumn{2}{|c|}{ Fixed parameter } \\
\hline \multicolumn{10}{|l|}{ (Reference category: None) } \\
\hline \multicolumn{10}{|l|}{ Primary Healthcare Practitioner } \\
\hline Psychologist & PSYCHOL & 0.438 & $*$ & 0.188 & 2.330 & 0.715 & $*$ & 0.321 & 2.230 \\
\hline Psychiatrist & PSYCHIA & 0 & & \multicolumn{2}{|c|}{ Fixed parameter } & 0 & & \multicolumn{2}{|c|}{ Fixed parameter } \\
\hline \multicolumn{10}{|l|}{ (Reference category: GP) } \\
\hline \multicolumn{10}{|l|}{ Monthly out of pocket cost } \\
\hline$\$ 250$ & CST250 & -0.181 & & 0.245 & -0.740 & 0.660 & $*$ & 0.374 & 1.770 \\
\hline$\$ 500$ & CST500 & -0.181 & & 0.245 & -0.740 & -1.219 & $*$ & 0.563 & -2.170 \\
\hline$\$ 750$ & CST750 & -0.818 & $*$ & 0.301 & -2.720 & -2.704 & $*$ & 1.055 & -2.560 \\
\hline$\$ 1000-\$ 2500$ & CST 1000 & -1.398 & $*$ & 0.254 & -5.500 & -3.927 & $*$ & 1.068 & -3.680 \\
\hline \multicolumn{10}{|l|}{ (Reference category: $\$ 100$ ) } \\
\hline \multicolumn{10}{|c|}{ Class assignment parameters } \\
\hline Constant & & -0.003 & & 0.523 & -0.010 & 0 & & \multicolumn{2}{|c|}{ Fixed parameter } \\
\hline \multicolumn{10}{|l|}{ Area of residence } \\
\hline Metro & & 1.280 & & 0.697 & 1.840 & 0 & & \multicolumn{2}{|c|}{ Fixed parameter } \\
\hline (Reference category: regional) & & & & & & & & & \\
\hline
\end{tabular}

(Continued) 
Table 4 (Continued).

\begin{tabular}{|c|c|c|c|c|c|c|c|c|}
\hline \multirow{3}{*}{$\begin{array}{l}\text { Class Proportions } \\
\text { Utility Parameters }\end{array}$} & \multirow[t]{3}{*}{ Symbol } & \multicolumn{4}{|c|}{ Class I } & \multicolumn{3}{|c|}{ Class 2} \\
\hline & & \multicolumn{4}{|c|}{0.584} & \multicolumn{3}{|c|}{0.416} \\
\hline & & Parameter & & SE & T-Ratio & Parameter & SE & T-Ratio \\
\hline \multicolumn{9}{|l|}{ Age } \\
\hline Under 45 years & & -1.585 & $*$ & 0.762 & -2.080 & 0 & \multicolumn{2}{|c|}{ Fixed parameter } \\
\hline
\end{tabular}

Notes: *Statistically significant at the 5\%-level. Restricted log-likelihood: -659.167 ; Log-likelihood: -424.462 ; McFadden Pseudo R-squared: 0.356. Number of respondents: 75; Number of choice observations: 600 . All categorical attributes were dummy coded and should be compared to the reference category. Omitted attributes: remission, psychotherapy, lifestyle changes, mindfulness and treatment setting.

(explanations of beta coefficients can also be found in Table 4). The larger the coefficient, the more impact it has on utility.

$$
\begin{aligned}
U(\text { PlanA })= & \beta_{E F 50} x_{E F 50}+\beta_{E F 70} x_{E F 70}+\beta_{O R A L} x_{O R A L} \\
& +\beta_{N A S A L} x_{N A S A L}+\beta_{I N F} x_{I N F}+\beta_{E C T} x_{E C T} \\
& +\beta_{T M S} x_{T M S}+\beta_{P S Y C H O L} x_{P S Y C H O L} \\
& +\beta_{P S Y C H I A} x_{P S Y C H I A}+\beta_{C S T 250} x_{C S T 250} \\
& +\beta_{C S T 500} x_{C S T 500}+\beta_{C S T 750} x_{C S T 750} \\
& +\beta_{C S T 1000} x_{C S T 1000} \\
U(\text { PlanB })= & \beta_{E F 50} x_{E F 50}+\beta_{E F 70} x_{E F 70}+\beta_{O R A L} x_{O R A L} \\
& +\beta_{\text {NASAL }} x_{N A S A L}+\beta_{I N F} x_{I N F}+\beta_{E C T} x_{E C T} \\
& +\beta_{T M S} x_{T M S}+\beta_{P S Y C H O L} x_{P S Y C H O L} \\
& +\beta_{P S Y C H I A} x_{P S Y C H I A}+\beta_{C S T 250} x_{C S T 250} \\
& +\beta_{C S T 500} x_{C S T 500}+\beta_{C S T 750} x_{C S T 750} \\
& +\beta_{C S T 1000} x_{C S T 1000} \\
& \\
& U(\text { Current })=\beta_{C O N}
\end{aligned}
$$

The average class assignment probabilities were $58.4 \%$ for class 1 and $41.6 \%$ for class 2 . Age and area of residence were significantly associated with class membership. Participants aged 45 years and older and those living in a metropolitan area were more likely to belong to class 1 , while those younger than 45 years and those living in a regional or rural area were more likely to belong to class 2.

Overall, participants in both classes strongly preferred plans that were highly effective $(50 \%$ or $70 \%$ improvement in mood symptoms compared to those with $30 \%$ improvement); managed by a psychologist rather than their GP; and had lower monthly out-of-pocket costs. Participants in class 1 preferred hypothetical alternative treatment plans $\mathrm{A}$ and $\mathrm{B}$ over their current treatment plan (holding all else equal; -1.189 , SE 0.340). They preferred plans without electroconvulsive therapy (ECT) $(-0.743$,
SE 0.240) and those that included nasal spray or oral medications to those that included no medications $(0.505$, SE 0.188 and 0.800 , SE 0.212 , respectively). Participants in class 2 were more likely to choose to stay with their current treatment plan (1.697, SE 0.443; Table 4). Attributes that did not significantly affect treatment preferences in either class included remission, psychotherapy, lifestyle changes, mindfulness and treatment setting (all $p>0.05)$. These attributes were removed in the final model and omitted from the LCM model output in Table 4.

Similar to the medication DCE, cost and effectiveness were the most important attributes for participants when considering the proposed treatment plans (Figure 4). For class 1, cost and effectiveness had a roughly equal amount of influence on decisions ( $27 \%$ and $35 \%$, respectively), followed by the inclusion of medication (15\%), brain stimulation (14\%) and who would be the primary healthcare practitioner (8\%). This was in contrast to participants in class 2 , who predominantly based their choice on cost (61\%) and distributed almost equally the remaining focus between effectiveness (14\%), who would be the primary healthcare practitioner $(9 \%)$, the inclusion of medication (8\%) and brain stimulation (7\%).

\section{Discussion}

Overall, cost and treatment effectiveness were identified as the most important features for participants when choosing between treatments for TRD. Despite the dominance of these attributes, heterogeneity was detected in behavior throughout both the medication and treatment plan DCEs.

In the medication DCE, participants in class 1 were tentative about giving up their current treatment (but could be persuaded to switch if presented with an alternative with a high rate of effectiveness), while those in class 2 were open to considering new treatments. In both classes, cost and effectiveness of treatment were much more 


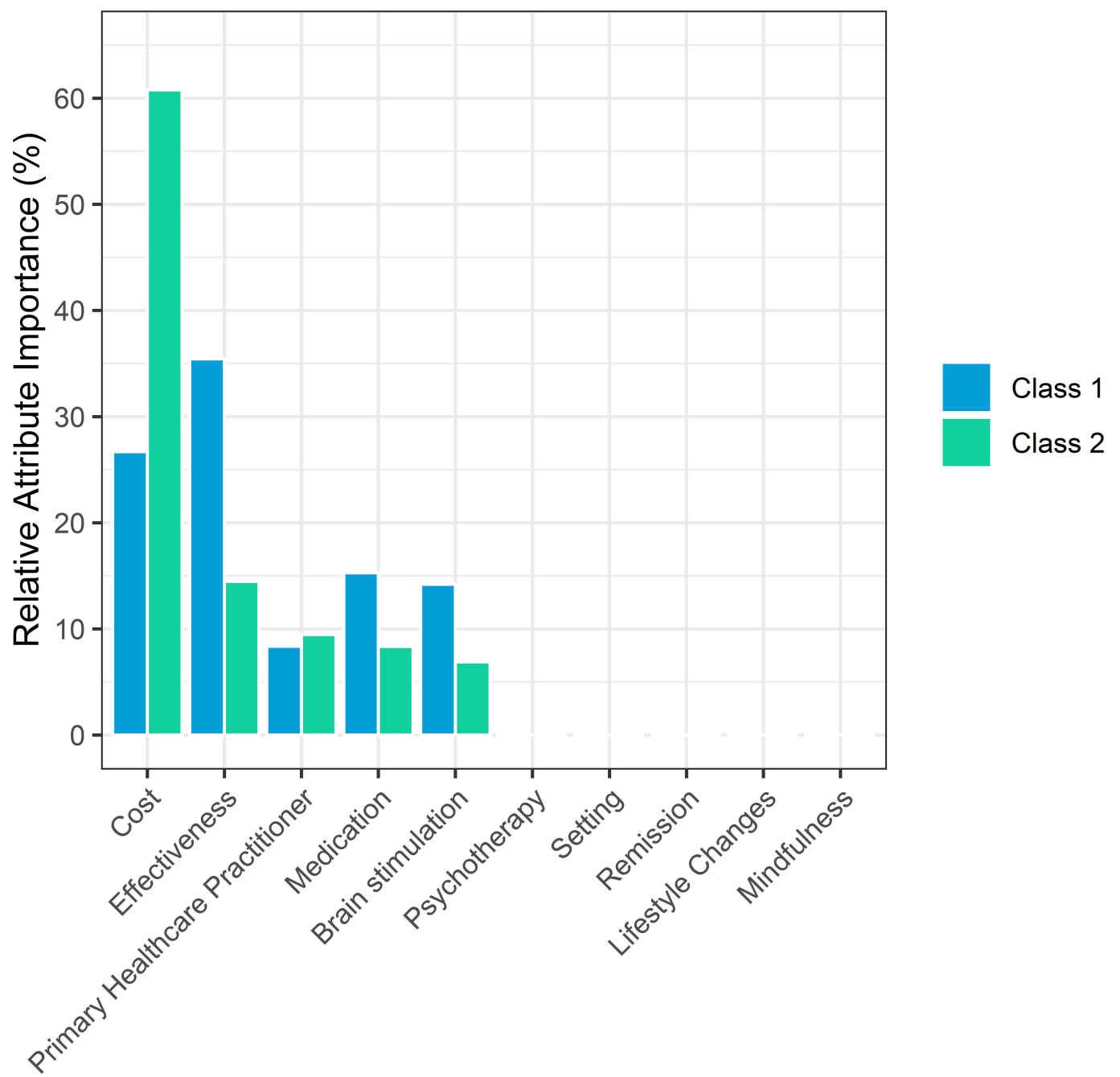

Attribute

Figure 4 Attribute importance for treatment plan DCE.

Note: Total is not shown because the class assignment model should be used to probability weight the segments based on specific characteristics.

important in influencing medication choice than attributes such as frequency of administration, onset of response and risk of certain side effects.

Across both classes in the medication DCE, it is important to note that the nasal spray alternative was the most sensitive to increases in treatment effectiveness, while also being the least preferred alternative compared with oral and infusion alternatives (holding all other things constant, based on the dashboard uptake). This could be due to a "believability" issue regarding nasal spray, where participants may perceive it to be inherently less effective than other modes of administration, possibly due to a lack of knowledge about this uncommon treatment. If the nasal spray's mechanism of action and effectiveness were explained, it may become more attractive to patients. Further research examining the influence of prior treatment experience on treatment choices is warranted.

In the treatment plan DCE, participants in class 1 were eager to switch to a new treatment plan and were influenced more by treatment effectiveness than cost. In direct contrast, participants in class 2 preferred to stay with their current treatment plan and were very cost sensitive, with a major decline in preferences if monthly out-of-pocket costs exceeded \$750. Again, some attributes had no significant effect on treatment preferences in either class (including remission, psychotherapy, lifestyle changes, mindfulness and treatment setting). It is important to note, however, that this does not equate to these attributes being unimportant to participants. Rather, due to the nature 
of the trade-off tasks, it may simply be that other attributes (such as effectiveness and cost) were more important in comparison.

Overall, participants were willing to compromise on treatment attributes such as side effects and convenience for a treatment that is affordable and efficacious in relieving the symptoms of TRD. People with TRD have, by definition, had inadequate responses to treatments, and there is an urgent need for a cost-effective therapy in this population.

The significant demographic influence on class membership in the treatment plan DCE may help understand the observed choice behavior in class 2 , particularly when it concerns the influence of the cost of a medication or therapy on the treatment choice. People with mental illnesses may be significantly financially disadvantaged compared with the general community, and cost is a recognized barrier to care for people with mental illness in Australia. ${ }^{31}$ In addition, people living in rural and remote areas face significantly higher costs when accessing mental health care compared with people living in

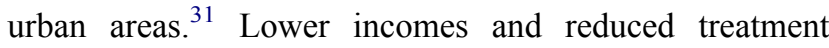
availability and accessibility in rural and remote parts of Australia may explain preferences towards lower cost treatments that do not require frequent clinic visits, but further data is needed to confirm this.

The relative importance of different treatment attributes should be considered when having treatment discussions with people with TRD. Our study findings suggest that rate of remission and risk of weight gain should be addressed when discussing oral medications; and treatment plan discussions should cover the inclusion of specific therapies and the primary healthcare provider who would deliver them. Understanding which features influence treatment choices and providing patients with specific information that addresses these features may improve treatment adherence and patient outcomes. ${ }^{2,5}$

Our study helps address the paucity of DCE studies examining preferences for depression treatments. ${ }^{15,32}$ DCEs, which offer an empirical and systematic method of examining preferences across different types of available treatments, are increasingly used to examine people's preferences for health treatments and further studies of this type can improve our knowledge of patient preferences in depression.

\section{Limitations}

This study has some limitations. Due to the nature of the study design, the sample may not be representative of the TRD population in Australia. The results may be biased to people who are more active in their self-management or those with certain socio-economic characteristics. Participants able to take part in online surveys may also have less cognitive impairment and more insight, and thus may represent a higher functioning sample than that of all people living with TRD. There is also potential bias for people who chose not to participate, which may reflect a group of patients that is actually indifferent about treatment choice or had less motivation to participate due to more severe depression.

In addition, our sample included more men than women, which does not reflect the population ratio of TRD in Australia. Other possible limitations were the inclusion of four people who had previously experienced a major depressive episode, as well as the exclusion of patients with certain comorbidities (it was considered that these comorbidities may have affected the treatments participants would have trialed, their past responses to treatments and perceptions of current and future treatment). We cannot be completely certain that each participant had been formally diagnosed with TRD by a clinician, albeit we are confident that the inclusion criteria was strict enough to approximate a TRD population as faithfully as possible in a study of this nature.

Furthermore, we cannot be certain that the participants properly understood the treatment options presented, despite explanation of attributes, pilot testing, and clear understanding of follow-up questions. It is also possible that all relevant attributes were not tested in our model. These factors, in addition to the relatively small sample size, should be considered when discussing applicability of these results to everyday practice.

\section{Conclusion}

Across both the medication and treatment plan DCEs, the segmentation between the two types of decision makers provides a strong foundation for understanding the different needs of people experiencing TRD. This study shows that while it is important to discuss the different attributes of particular treatment options, clinicians should pay special care in discussing the cost and effectiveness of treatment choices.

The results from this study could be used to better understand how preference heterogeneity among people with TRD may be used to guide informed decisions regarding the value of new and existing medications for TRD, and how they sit in the context of treatment plans. Furthermore, preference data from studies such as ours - the first of this type focusing on TRD in Australia - can be used to help guide health policy and possibly shared decision making in the future. 


\section{Acknowledgments}

The authors thank Anne Dyson, MBBS of WriteSource Medical Pty Ltd, Sydney, Australia, for providing medical writing services. Medical writing support was funded by Janssen Australia and New Zealand in accordance with Good Publication Practice (GPP3) guidelines (http://www. ismpp.org/gpp3).

\section{Funding}

The authors disclosed receipt of the following financial support for the research, authorship, and/or publication of this article: this work was supported by Janssen-Cilag Australia and New Zealand.

\section{Disclosure}

AP, VS and MA are employees of Janssen-Cilag, Australia and New Zealand. SF and AC are employees of CaPPRe, who were contracted by Janssen-Cilag to conduct the research. CaPPRe has consulted to AbbVie, Amgen, AstraZeneca, Celgene, GlaxoSmithKline, Ipsen, Roche, Sanofi and Shire outside of the submitted work. CHN has previously provided consulting services for Lundbeck, Grünbiotics, Servier, Janssen-Cilag and Eli Lilly; received research grant support from Wyeth and Lundbeck; and received speaker honoraria from Servier, Lundbeck, Bristol Myers Squib, Organon, Eli Lilly, GlaxoSmithKline, Janssen-Cilag, AstraZeneca and Pfizer. JG received an hourly rate for reviewing patient suitability for the qualitative component of the study from CaPPRe Pty Ltd. She is also the principal investigator for a Janssen Cilag trial involving esketamine and reports honorarium for being part of the Janssen Cilag advisory board. The authors report no other conflicts of interest in this work.

\section{References}

1. Rush AJ, Trivedi MH, Wisniewski SR, et al. Acute and longer-term outcomes in depressed outpatients requiring one or several treatment steps: a STAR*D report. Am J Psychiatry. 2006;163(11):1905-1917. doi:10.1176/ajp.2006.163.11.1905

2. Winter SE, Barber JP. Should treatment for depression be based more on patient preference? Patient Prefer Adherence. 2013;7:1047-1057. doi:10.2147/PPA.S52746

3. Geers AL, Rose JP, Fowler SL, Rasinski HM, Brown JA, Helfer SG. Why does choice enhance treatment effectiveness? Using placebo treatments to demonstrate the role of personal control. J Pers Soc Psychol. 2013;105(4):549-566. doi:10.1037/a0034005

4. Say RE, Thomson R. The importance of patient preferences in treatment decisions--challenges for doctors. BMJ. 2003;327(7414):54 2-545. doi:10.1136/bmj.327.7414.542
5. Orygen The National Centre of Excellence in Youth Mental Health. Clinical practice in youth mental health: Shared decision making. Orygen - The National Centre of Excellence in Youth Mental Health; Published 2016. Available from: https://orygen.org.au/Training/ Resources/General-resources/Clinical-practice-points/Shareddecision-making. Accessed January 21, 2020.

6. Hoffmann TC, Legare F, Simmons MB, et al. Shared decision making: what do clinicians need to know and why should they bother? Med J Aust. 2014;201(1):35-39. doi:10.5694/mja14.00002

7. Malhi GS, Bassett D, Boyce P, et al. Royal Australian and New Zealand College of Psychiatrists clinical practice guidelines for mood disorders. Aust N Z J Psychiatry. 2015;49(12):1087-1206.

8. Malhi GS, Bell E, Bassett D, et al. The 2020 Royal Australian and New Zealand College of Psychiatrists clinical practice guidelines for mood disorders. Aust N Z J Psychiatry. 2021;55(1):7-117. doi:10. $1177 / 0004867420979353$

9. Elwyn G, Frosch D, Thomson R, et al. Shared decision making: a model for clinical practice. J Gen Intern Med. 2012;27 (10):1361-1367. doi:10.1007/s11606-012-2077-6

10. Lindhiem O, Bennett CB, Trentacosta CJ, McLear C. Client preferences affect treatment satisfaction, completion, and clinical outcome: a meta-analysis. Clin Psychol Rev. 2014;34(6):506-517. doi:10.1016/ j.cpr.2014.06.002

11. Windle E, Tee H, Sabitova A, Jovanovic N, Priebe S, Carr C. Association of patient treatment preference with dropout and clinical outcomes in adult psychosocial mental health interventions: a systematic review and meta-analysis. JAMA Psychiatry. 2020;77 (3):294-302. doi:10.1001/jamapsychiatry.2019.3750

12. Gelhorn HL, Sexton CC, Classi PM. Patient preferences for treatment of major depressive disorder and the impact on health outcomes: a systematic review. Prim Care Companion CNS Disord. 2011;13(5).

13. Dwight-Johnson M, Sherbourne CD, Liao D, Wells KB. Treatment preferences among depressed primary care patients. $J$ Gen Intern Med. 2000;15(8):527-534. doi:10.1046/j.1525-1497.2000.08035.x

14. Yrondi A, Rieu J, Massip C, Bongard V, Schmitt L. Depressed patients' preferences for type of psychotherapy: a preliminary study. Patient Prefer Adherence. 2015;9:1371-1374. doi:10.2147/PPA.S87270

15. Zimmermann TM, Clouth J, Elosge M, et al. Patient preferences for outcomes of depression treatment in Germany: a choice-based conjoint analysis study. $J$ Affect Disord. 2013;148(2-3):210-219. doi:10.1016/j.jad.2012.11.062

16. Ionescu DF, Rosenbaum JF, Alpert JE. Pharmacological approaches to the challenge of treatment-resistant depression. Dialogues Clin Neurosci. 2015;17(2):111-126.

17. Fekadu A, Donocik JG, Cleare AJ. Standardisation framework for the Maudsley staging method for treatment resistance in depression. BMC Psychiatry. 2018;18(1):100. doi:10.1186/s12888-018-1679-x

18. Thurstone LL. A law of comparative judgment. Psychol Rev. 1927;34 (4):273. doi:10.1037/h0070288

19. Lancaster KJ. A new approach to consumer theory. J Political Econ. 1966;74(2):132-157. doi:10.1086/259131

20. McFadden D. Conditional logit analysis of qualitative choice behaviour. In: Zarembka P, editor. Frontiers of Econometrics. New York: Academic Press; 1974:105-142.

21. Soekhai V, de Bekker-grob EW, Ellis AR, Vass CM. Discrete choice experiments in health economics: past, present and future. PharmacoEconomics. 2019;37(2):201-226.

22. Coast J, Al-Janabi H, Sutton EJ, et al. Using qualitative methods for attribute development for discrete choice experiments: issues and recommendations. Health Econ. 2012;21(6):730-741. doi:10.1002/ hec. 1739

23. Chandler GM, Iosifescu DV, Pollack MH, Targum SD, Fava M. RESEARCH: validation of the Massachusetts General Hospital Antidepressant Treatment History Questionnaire (ATRQ). CNS Neurosci Ther. 2010;16(5):322-325. doi:10.1111/j.1755-5949.2009. 00102.x 
24. Orme B. Getting Started with Conjoint Analysis: Strategies for Product Design and Pricing Research. Fourth ed. Madison, Wisconsin: Research Publishers LLC; 2010; 2019.

25. Rose JM, Bliemer MC. Constructing efficient stated choice experimental designs. Transport Rev. 2009;29(5):587-617. doi:10.1080/ 01441640902827623

26. Bridges JF, Hauber AB, Marshall D, et al. Conjoint analysis applications in health--a checklist: a report of the ISPOR Good Research Practices for Conjoint Analysis Task Force. Value Health. 2011;14 (4):403-413. doi:10.1016/j.jval.2010.11.013

27. Reed Johnson F, Lancsar E, Marshall D, et al. Constructing experimental designs for discrete-choice experiments: report of the ISPOR Conjoint Analysis Experimental Design Good Research Practices Task Force. Value Health. 2013;16(1):3-13. doi:10.1016/j. jval.2012.08.2223

28. Royal Australian and New Zealand College of Psychiatrists. Keeping your head above water: affordability as a barrier to mental health care; 2014. Available from: https://www.ranzcp.org/files/resources/ reports/keeping-your-head-above-water-affordability-as-a.aspx. Accessed June 30, 2021.

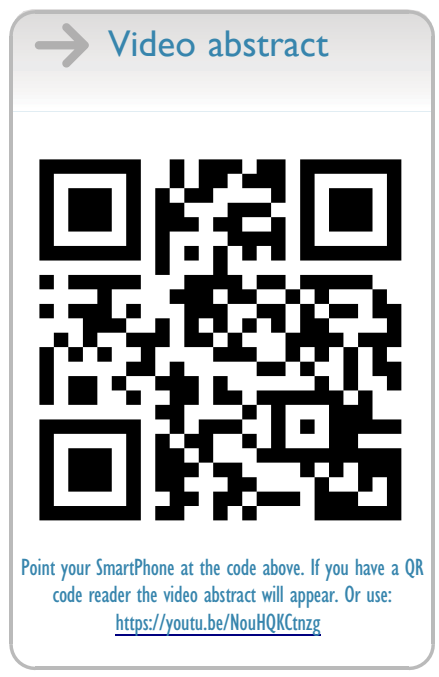

29. Revicki DA, Wood M. Patient-assigned health state utilities for depression-related outcomes: differences by depression severity and antidepressant medications. J Affect Disord. 1998;48(1):25-36. doi:10.1016/S0165-0327(97)00117-1

30. Morey E, Thacher JA, Craighead WE. Patient preferences for depression treatment programs and willingness to pay for treatment. $J$ Ment Health Policy Econ. 2007;10(2):73-85.

31. Wittink MN, Cary M, Tenhave T, Baron J, Gallo JJ. Towards patient-centered care for depression: conjoint methods to tailor treatment based on preferences. Patient. 2010;3(3):145-157. doi:10.2165/ 11530660-000000000-00000

32. Eiring O, Landmark BF, Aas E, Salkeld G, Nylenna M, Nytroen K. What matters to patients? A systematic review of preferences for medication-associated outcomes in mental disorders. BMJ Open. 2015;5(4):e007848. doi:10.1136/bmjopen-2015-007848
Patient Preference and Adherence

\section{Publish your work in this journal}

Patient Preference and Adherence is an international, peer-reviewed, open access journal that focusing on the growing importance of patient preference and adherence throughout the therapeutic continuum. Patient satisfaction, acceptability, quality of life, compliance, persistence and their role in developing new therapeutic modalities and compounds to optimize clinical outcomes for existing disease

\section{Dovepress}

states are major areas of interest for the journal. This journal has been accepted for indexing on PubMed Central. The manuscript management system is completely online and includes a very quick and fair peer-review system, which is all easy to use. Visit http:// www.dovepress.com/testimonials.php to read real quotes from published authors. 